\title{
Nematicidal Activity and Phytochemistry of Greek Lamiaceae Species
}

\author{
Nikoletta G. Ntalli ${ }^{1}{ }^{*}$, Efstathia X. Ozalexandridou ${ }^{2}$, Konstantinos M. Kasiotis ${ }^{3}{ }^{(1)}$, \\ Maria Samara ${ }^{1}$ (D) and Spyros K. Golfinopoulos ${ }^{2,4, *(D)}$ \\ 1 Laboratory of Biological Control of Pesticides, Department of Pesticides Control and Phytopharmacy, \\ Benaki Phytopathological Institute, 8 S. Delta Str., 14561 Athens, Greece; m.samara@bpi.gr \\ 2 School of Sciences and Technology, Hellenic Open University, 18 Parodos Aristotelous st., \\ 26335 Patra, Greece; e.ozalexandridou@gmail.com \\ 3 Laboratory of Pesticides' Toxicology, Department of Pesticides Control and Phytopharmacy, \\ Benaki Phytopathological Institute, 8 S. Delta Str., 14561 Athens, Greece; k.kasiotis@bpi.gr \\ 4 Department of Financial and Management Engineering, School of Engineering, University of the Aegean, \\ 41 Kountourioti st., 82132 Chios, Greece \\ * Correspondence: nntali@agro.auth.gr (N.G.N.); s.golfinopoulos@fme.aegean.gr (S.K.G.); \\ Tel.: +30-210-818-0343 (N.G.N.); +30-227-103-5459 (S.K.G.)
}

Received: 23 June 2020; Accepted: 30 July 2020; Published: 1 August 2020

\begin{abstract}
Natural pesticides are in the forefront of interest as ecofriendly alternatives to their synthetic ancestors. In the present study, we evaluated the nematicidal activity of seven Greek Lamiaceae species and discerned among principal components for activity according to GC-MS analysis. Care was taken that all botanicals used were easily prepared without employing elaborate procedures and toxic solvents. We established the in vitro $\mathrm{EC}_{50}$ values of the hydrosols of Origanum vulgare L., Mentha piperita L. and Melissa officinalis L. and the water extracts of Origanum vulgare, Thymus vulgaris L., Thymus citriodorus (Schreb), Rosmarinus officinalis (Spenn), and Ocimum basilicum L. against Meloidogyne javanica (Treub) and Meloidogyne incognita (Kofoid \& White). Furthermore, we amended nematode-infested soil with powdered leaves and flowers of $O$. vulgare to assess for efficacy. According to in vitro studies, the most active botanical preparations against both nematode species was $O$. vulgare, as regards its hydrosol and water extract. Thymus citriodorus was proved very potent against $M$. javanica, provoking $100 \%$ paralysis at $4 \mu \mathrm{L} / \mathrm{mL}$ after $96 \mathrm{~h}$, but was only nematostatic against $M$. incognita since the second-stage juveniles (J2s) recovered movement $48 \mathrm{~h}$ after immersion in test solutions. Interestingly, O. vulgare was also proved nematicidal in pot bioassays but at test concentrations over $50 \mathrm{~g} / \mathrm{kg}$ was phytotoxic for tomato plants. According to GC-MS analysis, the principal components sustaining activity of $O$. vulgare are carvacrol and thymol. The nematicidal activity of $O$. vulgare seems promising in the forms of essential oil leftovers (i.e., hydrosol), self-prepared water extract that can be of consideration as $\alpha$ "basic substance", and powder for soil amendment.
\end{abstract}

Keywords: natural substances; nematicidal; root-knot nematodes; oregano; soil amendments; basic substances

\section{Introduction}

Nematodes are among the most complex and numerous organisms on the planet. The name Nematoda, or Nematelminthes, is derived from the Greek word " $\eta \mu \alpha$ " (thread or threadworms). They belong to the kingdom Animalia, phylum Nematoda [1]; and after arthropods, they form the second most numerous group of Metazoa. They have the form of a worm, with a cylindrical, elongated body and a circular cross-section. Their diffusion on earth is wide due to their ability to adapt easily 
due to their inner and outer morphology [2]. Nematode species that cause damage to cultivated plant species are called plant-parasitic nematodes. Root-knot nematodes (Meloidogyne sp.) cause considerable damage to more than 5000 plant species and use their stylets to feed on the roots of the plants. [3]. Meloidogyne incognita, M. javanica, and M. arenaria infect Solanaceae and Malvaceae, have broad host ranges, and are in the list of the most economically damaging root-knot nematodes [4]. On the other hand, tomato is one of the most significant crop hosts of Meloidogyne spp. and in the presence of disease complexes with soil pathogens the subsequent damages may even lead to total crop loss [5].

Plant nematodes are not controlled using just one method but are tackled by a combination of methods in the context of an integrated system for management of harmful organisms [6]. Although many synthetic pesticides have been used in the past as chemical nematicides, only a few are still authorized according to European legislation [7]. This fact creates an urgent need for discovering less toxic and environmentally friendly substitutes for commercial use [8]. The use of plant secondary metabolites, as well as the reutilization of culture's debris can potentially constitute a powerful weapon for plant protection. Efforts for a transition to an environmentally friendly crop protection pave a new way towards pest control. The essential oils (EOs) of aromatic plants are used in many fields because of their antimicrobial, antifungal, antioxidant, and antibacterial activities [9]. The biological activity of EOs is related to their chemical composition, which is influenced by the specific climatic, seasonal, and geographic conditions affecting the aromatic species from which EOs derive [10]. It is accepted that the EOs exhibit efficacy against insects [11] and nematodes [12]. We have previously shown that the EOs of the family Lamiaceae, including the species Mentha pulegium L., Origanum vulgare, Origanum dictamnus L. and Melissa officinalis display powerful in vitro nematicidal activity [13]. In another study using material from different botanical families, a consistent suppression of $M$. incognita population on tomato roots was evident after soil drench treatments with water emulsions of EOs from Schinus molle L., Cinnamomum camphora L., Eugenia caryophillata L., Cinnamomum zeylanicum (J. Presl), and Citrus aurantium L. [14]. Likewise, the EOs of Eucalyptus citriodora Hook, Eucalyptus globulus (), Mentha piperita, Pelargonium asperum (L'Hér), and Ruta graveolens L. were proved to be nematicidal against M. incognita [15], while Dysphania ambrosioides L., Filipendula ulmaria L., Ruta graveolens, Satureja montana $\mathrm{L}$. and Thymbra capitata $\mathrm{L}$. EOs revealed $\mathrm{EC}_{50}$ values lower than $0.15 \mu \mathrm{L} / \mathrm{mL}$ against root-knot nematodes according to Faria et al. [16]. The bioactive EOs' principal components are the terpenes, playing an essential protective role for the plants [17]; their significant synergistic and/or antagonistic activities compose the overall efficacy against target organisms $[18,19]$.

According to SANCO draft working document 10472, reduced data requirements are described for plant protection products made from all edible parts of plants of human and animal feed. The document refers to plant extracts made with water or ethanol from parts of plants currently authorized as herbal drugs according to European Pharmacopoeia. This manufacturing process (e.g., crushing, drying, and water and/or ethanol extraction) is not considered to modify the toxicity or ecotoxicity profiles [20,21]. Moreover, the regulation 1107/2009 (EC2009) contains some facilitation for "low-risk active substances" and for "basic substances", that is, "nematicidal recipes" prepared by the farmer with low risk of harmfulness for soil, water, air, plants, or animals [22]. In this frame, water extracts prepared from O. vulgare and T. citriodorus may plausibly be developed as "low-risk plant protection products" or "basic substances".

The aim of this study was to examine the nematicidal effect of botanical extracts that are easily prepared from seven Greek Lamiaceae species without employing elaborate procedures and toxic solvents. Interestingly, we used T. citriodorus in a recent study to test for nematicidal activity against M. incognita and M. javanica, but with a different extraction protocol [23], thus herein we evaluate any subsequent differences in activity. Specifically we study the in vitro nematicidal activity of the hydrosols of Origanum vulgare, Mentha piperita, and Melissa officinalis and the water extracts of Origanum vulgare, Thymus vulgaris, Thymus citriodorus, Rosmarinus officinalis and Ocimum basilicum against Meloidogyne javanica and Meloidogyne incognita. Furthermore, we evaluate in planta the most 
effective botanical species, i.e., O. vulgare, in the form of powdered leaves and flowers amended into soil that has been artificially infested by nematodes and assess for efficacy. The outcomes of the study are self-prepared water-based extracts that can be of consideration as "basic substances" or "low-risk" active ingredients for plant protection products, as well as soil bio-amendment practices that can plausibly be integrated into IPM schemes and/or organic farming.

\section{Materials and Methods}

\subsection{Aromatic Materials}

The aromatic materials tested for the nematicidal activity against $M$. javanica and M. incognita include: (a) hydrosols obtained as aquatic leftovers after EO obtainment from Clevenger distillation of Origanum vulgare, Mentha piperita, and Melissa officinalis from the Aitheria Company based in Velvento, Kozani, Greece, and (b) water extracts from powdered plant parts of Origanum vulgare, Thymus vulgaris, Thymus citriodorus, Rosmarinus officinalis, and Ocimum basilicum obtained from the Ethericon Greek Herbs company based in Larisa, Greece.

\subsection{Plant Extraction}

The extraction of plant powders was performed with the Sonicator Branson 2510 ultrasound device. Initially, $5 \mathrm{~g}$ of plant residue powder was weighed and placed in a beaker with $25 \mathrm{~mL}$ of water, forming a ratio of $1 / 25(w / v)$. The mixture was carefully stirred in order to ensure even distribution and placed in the Sonicator device. Afterwards, distilled water was added to the volume needed to surpass the surface of the solvent in the beaker, and the mixture was sonicated for $15 \mathrm{~min}$. Finally, the water extract was obtained by filtering through cotton (filtering had no effect on the recovery of the constituents assessed by GC-MS). To proceed to GC-MS chemical analysis, water extracts and hydrosols were subjected to subsequent extraction with two portions of petroleum ether ( $25 \mathrm{~mL}$ each). The combined organic phases were dried $\left(\mathrm{MgSO}_{4}\right)$, evaporated to dryness using $\mathrm{N}_{2}$ stream, filtered with Chromafil syringe Nylon filter $(0.22 \mu \mathrm{m}$, Macherey Nagel GmbH \& Co. KG, Düren, Germany), and injected into the GC-MS system.

\subsection{Nematode Culture}

A population of M. javanica and another of M. incognita were obtained upon a single eggmass per species and were reared on tomato (Solanum lycopersicum L.) cv Belladonna, a variety that is particularly sensitive to root-knot nematodes. The tomato plants used for the development of the population of root-knot nematodes were maintained in a growth chamber at $25-28{ }^{\circ} \mathrm{C}, 60 \%$ relative humidity and $16 \mathrm{~h}$ photoperiod in plastic plant pots $(18 \mathrm{~cm}$ diameter) containing a 10:1 $(\mathrm{v} / \mathrm{v})$ mixture of peat and pearlite. These conditions remained stable at these levels throughout the whole duration of the experiments. Plants used for inoculations were 7 weeks old, at the five-leaf stage. After 40 days, the plants were uprooted, and the roots were washed to remove any soil residue and cut into $2 \mathrm{~cm}$ pieces. The roots were placed in a solution of $1 \%$ sodium hypochlorite, and the suspension was shaken for $5 \mathrm{~min}$. Then, it was washed in running water through nested sieves of a 250 and $38 \mu \mathrm{m}$ cross-section, and the eggs of the nematodes were recovered and finally transferred in Baermann modified funnels at $28^{\circ} \mathrm{C}$ [24]. The water suspension with the nematode eggs was placed in filter paper inside a sieve ( $2 \mathrm{~mm}$ hole size) and secured in a plastic tray with distilled water. All second-stage juveniles (J2s) hatching in the first 3 days were discarded. After an additional $24 \mathrm{~h}, \mathrm{~J} 2 \mathrm{~s}$ were collected and used in the experiments.

\subsection{J2 Paralysis}

Appropriate amounts of hydrosol and extract solutions were used in order to achieve the concentration range for $\mathrm{EC}_{50}$ calculation. The solutions were mixed with the suspension of nematodes, in the wells of a polystyrene plate of 96-well plates at a ratio 1:1 $(v / v)$, and the final volume per well 
was $140 \mu \mathrm{L}$. Each test solution was $2 \times$ so as to reach the expected concentration after mixing with the nematode suspension.

Five replicates were performed on five concentration levels covering the range of 25 to $200 \mu \mathrm{L} / \mathrm{mL}$ for all treatments. Regarding the best effective ones, which were the water extracts of $O$. vulgare and T. citriodorus, the $\mathrm{EC}_{50}$ values were finally established using the test concentration range of 3.9, 7.8, 15.6, 31.2 , and $62.5 \mu \mathrm{L} / \mathrm{mL}$. Distilled water was used as control, and the nematode number per experimental well was $15-20 \mathrm{~J} 2 \mathrm{~s}$. The plates were covered with a lid, so as to prevent evaporation which would differentiate final test concentrations, and intermediate wells were used to immerse $\mathrm{J} 2$ in water so as to control cross-contamination between treatments due to the volatility. The plates were placed in a chamber with stable conditions at $28^{\circ} \mathrm{C}$. $\mathrm{J} 2$ paralysis was assessed by observation in a reverse microscope (Euromex, Holland) at 40× zoom at the timepoints of 24, 48, and $96 \mathrm{~h}$ after establishment of the experiment. The J2s were classified into two categories: motile and paralyzed. Paralysis assessed after $96 \mathrm{~h}$ of immersion was characterized as death if J2s never regained motility after significantly augmenting the water volume in immersion solutions for an additional $24 \mathrm{~h}$.

\subsection{Soil Amendment with O. vulgare Powder for M. incognita Control and Phytotoxicity to Tomato Plants}

The sandy loam soil (18\% clay, $22 \%$ silt, $60 \%$ sand), with pH $6.5,3.3 \%$ organic carbon, and $1.9 \mathrm{mg} \mathrm{g}^{-1}$ total N, was collected from a noncultivated field of the Benaki Phytopathological Institute. Initially, it was sieved through a $3 \mathrm{~mm}$ sieve and partially air dried overnight; then, a mixture with sand at a ratio of 2:1 was prepared to form the hereafter referred to soil. Six plastic bags represented the experimental treatments, $1 \mathrm{~kg}$ of soil each receiving a nematode inoculation of $2500 \mathrm{~J} 2 \mathrm{~s} \mathrm{per} \mathrm{kg}$. After appropriate mixing and overnight incubation at room temperature, according to Ntalli et al. [23], the plastic bags were spiked with appropriate amounts of $O$. vulgare powder to reach the test concentrations of 1,5 , 10,50 , and $100 \mathrm{~g} \mathrm{~kg}^{-1}$ soil. A water control was also included in the experiment. Seven-week-old tomato plants, cv. Belladonna, were transplanted into the treated soil, separated in five different pots containing $200 \mathrm{~g}$ of soil each, and the bioassay was kept in an incubator at $27^{\circ} \mathrm{C}$ and $60 \%$ relative humidity at a $16 \mathrm{~h}$ photoperiod for 40 days. Every pot received $20 \mathrm{~mL}$ of water every 3 days for 40 days; afterwards, plants were uprooted and gently washed. Shoots were separated from roots and the latter were stained with acid fuchsin, according to Byrd et al. [25], and the following parameters were assessed: (a) M. incognita females per $\mathrm{g}$ of root at 10× magnification, (b) fresh stem weight, and (c) fresh root weight. The experiment was performed twice, and the treatments were arranged in a completely randomized design with five replicates.

\subsection{Gas Chromatography-Mass Spectrometry Analyses of Water Extracts (WEs) and Hydrosols (Hs)}

The GC-MS analysis was conducted on a Chromtech Evolution 3 MS/MS triple quadrupole mass spectrometer built on an Agilent 5975 B inert XL EI/CI MSD system that was operated in full scan data acquisition mode, within the mass range from $\mathrm{m} / \mathrm{z} 50$ to 500 . Samples were injected with a Gerstel MPS-2 autosampler using a $10 \mu \mathrm{L}$ syringe. Component separations were performed on the chromatographic column HP-5 ms Ultra-Inert (UI), with a length of $30 \mathrm{~m}$, inner diameter (ID) of $0.25 \mathrm{~mm}$, and film thickness of $0.25 \mu \mathrm{m}$ (J\&W Scientific, Folsom, CA, USA). Helium (99.9999\% purity) was used as the carrier gas at a flow rate of $1.2 \mathrm{~mL} \mathrm{~min}^{-1}$. The column oven temperature program initiated from $45^{\circ} \mathrm{C}$ and stayed there for $1 \mathrm{~min}$ before increasing at a rate of $5{ }^{\circ} \mathrm{C} \mathrm{min}-1$ to $250{ }^{\circ} \mathrm{C}$, where it stayed for $5 \mathrm{~min}$. The transfer line, manifold, and source of ionization temperatures were 300, 40 and $230{ }^{\circ} \mathrm{C}$, respectively. The electron multiplier voltage was set at $2000 \mathrm{~V}$. The total GC analysis time was $47 \mathrm{~min}$. Identified peaks in GC-MS (triplicate analysis) were verified by matching the acquired mass spectra with those in the commercial library of NIST 08. 


\subsection{Statistical Analysis}

Concerning the effect of the hydrosols and the aquatic extracts on J2 mobility, the experiments were repeated five times for each concentration level on an experimental project of completely randomized groups. The experiment was conducted twice.

For each paralysis test, the analysis of all data was correlated to time. The average of the two temporal repetitions for each experiment is presented, as the correlated analysis of variability did not show a significant interaction between the interventions and the execution time of the experiments.

For the statistical analysis and since the paralysis in the carrier did not differ from that measured in water, the paralysis data for both experiments were expressed as percentage rates of the paralysis values corresponding to the water control according to Schneider Orelli's equation [26]: Paralysis increase $\%=($ (paralysis $\%$ during treatment - paralysis $\%$ in the water control $) /(100-$ paralysis $\%$ in the water control) $) \times 100$.

Following the immersion in hydrosol and extract solutions, a variability analysis (ANOVA) was performed. Then the log-logistic equation of Seefeldt et al. [27] for the calculation of the values $\mathrm{EC}_{50}$ was used, according to the following equation: $\mathrm{Y}=\mathrm{C}+(\mathrm{D}-\mathrm{C}) /\left\{1+\exp \left[\mathrm{b}\left(\log (\mathrm{x})-\log \left(\mathrm{EC}_{50}\right)\right)\right]\right\}$ where $\mathrm{C}$ is the lower limit, $\mathrm{D}$ is the upper limit, $\mathrm{b}$ is the slope of line in value $\mathrm{EC}_{50}$, and $\mathrm{EC}_{50}$ is the concentration of the hydrosol or aquatic extract required for the $50 \%$ increase of paralyzed J2s compared with those of the water control.

In the particular regression equation, the concentration of the hydrosol or extract $(\mu \mathrm{g} / \mathrm{mL})$ was the independent factor $(x)$, and $\mathrm{J} 2$ immobility (percentage increase as compared to the water control) the dependent factor $(y)$.

Concerning the pot bioassays, the means were averaged over experiments, since ANOVAs showed no significant treatment between runs. Statistical analysis was performed using SPSS 20 (IBM, Armonk, NY, USA). Both ANOVA and Duncan's test were set at $p \leq 0.05$.

\section{Results and Discussion}

\subsection{In Vitro Nematicidal Activity}

Among all the seven species tested for their nematicidal activity, only O. vulgare and T. citriodorus have nematicidal activity at the concentration range tested ( 3.9 to $200 \mu \mathrm{L} / \mathrm{mL}$ ). Table 1 presents the effect on the paralysis of J2s after their immersion for 24,48 , and $96 \mathrm{~h}$ in test solutions. Paralysis reported after $96 \mathrm{~h}$ was irreversible in all cases. In most cases, the rate of $\mathrm{J} 2$ paralysis was proportionate to the increase of concentration and time of immersion in test solutions. Instead, plant extracts of M. piperita, M. officinalis, T. vulgaris, R. officinalis, and O. basilicum did not show activity in the test concentration range ( 25 to $200 \mu \mathrm{L} / \mathrm{mL}$ ). Thymus citriodorus water extract (WE) was the most effective against M. javanica, and the observed paralysis for J2s immersed at $3.9 \mu \mathrm{L} / \mathrm{mL}$ was $100 \%$ at $96 \mathrm{~h}$ after establishment of the experiment. In contrast, T. citriodorus was not found equally active on $M$. incognita since paralysis obtained at $24 \mathrm{~h}$ was reversible $48 \mathrm{~h}$ after establishment of the experiment.

In the same context, previously we studied T. citriodorus WE obtained with a different extraction protocol applying lower eluent volume $1 / 10(w / v)$, and the $\mathrm{EC}_{50 / 48 \mathrm{~h}}$ values were calculated to be 84.19 and $61.97 \mu \mathrm{L} / \mathrm{mL}$ against $M$. incognita and $M$. javanica, respectively [23]. In this study, T. citriodorus was extracted with water, using a ratio of $1 / 25(w / v)$, and the respective $\mathrm{EC}_{50 / 48 \mathrm{~h}}$ value against $M$. javanica was lower than the value previously reported; meanwhile it was found nematostatic against M. incognita. Consequently, it appears that the solvent volume affects extraction efficiency, influencing the equilibrium constant of the analytes' partitioning between the two phases [28]. In this case, the higher amount of solvent seems to yield higher extraction recoveries of the particular nematicidal components (i.e., a more concentrated extract, not affected under these conditions by the dilution), leading to higher activity against $M$. javanica. 
In fact, the WE of $O$. vulgare was the best effective against $M$. incognita, followed by $T$. citriodorus. Interestingly, O. vulgare hydrosol $(\mathrm{H})$ only achieved paralysis against $M$. javanica, but was found inactive against $M$. incognita. Origanum vulgare WE achieved better paralysis of $M$. incognita than T. citriodorus did. It should be noted that there was no cross-contamination between the treatments due to volatility, as the mobility of the J2s in the peripheral wells, where J2s were immersed in water, did not change.

Table 1. $\mathrm{EC}_{50}(\mu \mathrm{L} / \mathrm{mL})$ values of water extracts $(\mathrm{WE})$ and hydrosols $(\mathrm{H})$ against $M$. incognita and M. javanica, calculated after immersion of second-stage juveniles (J2s) in test solutions for 24, 48, and $96 \mathrm{~h}$. The test concentrations used for the $\mathrm{H}$ of $O$. vulgare were 25 to $200 \mu \mathrm{L} / \mathrm{mL}$, while for the water extracts of $O$. vulgare and T. citriodorus $3.9,7.8,15.6,31.2$, and $62.5 \mu \mathrm{L} / \mathrm{mL}$.

\begin{tabular}{|c|c|c|c|c|c|c|c|c|}
\hline \multicolumn{9}{|c|}{ H of O. vulgare on $M$. javanica } \\
\hline \multicolumn{3}{|c|}{$24 \mathrm{~h}$} & \multicolumn{3}{|c|}{$48 \mathrm{~h}$} & \multicolumn{3}{|c|}{$96 \mathrm{~h}$} \\
\hline $\mathrm{EC}_{50}(\mu \mathrm{L} / \mathrm{mL})$ & & $95 \%$ Conf Int & $\mathrm{EC}_{50}(\mu \mathrm{L} / \mathrm{mL})$ & & $95 \%$ Conf Int & $\mathrm{EC}_{50}(\mu \mathrm{L} / \mathrm{mL})$ & & $95 \%$ Conf Int \\
\hline 173.580 & 7.127 & $158.837-188.324$ & 151.196 & 8.550 & $133.510-168.883$ & 118.26 & 5.996 & $105.856-130.663$ \\
\hline \multicolumn{9}{|c|}{ WE of O. vulgare on M. javanica } \\
\hline \multicolumn{3}{|c|}{$24 \mathrm{~h}$} & \multicolumn{3}{|c|}{$48 \mathrm{~h}$} & \multicolumn{3}{|c|}{$96 \mathrm{~h}$} \\
\hline $\mathrm{EC}_{50}(\mu \mathrm{L} / \mathrm{mL})$ & & $95 \%$ Conf Int & $\mathrm{EC}_{50}(\mu \mathrm{L} / \mathrm{mL})$ & & $95 \%$ Conf Int & $\mathrm{EC}_{50}(\mu \mathrm{L} / \mathrm{mL})$ & & 95\% Conf Int \\
\hline na & & & 27.041 & 3.084 & $20.661-33.421$ & 37.844 & 5.091 & $27.312-48.375$ \\
\hline \multicolumn{9}{|c|}{ WE of O. vulgare on $M$. incognita } \\
\hline \multicolumn{3}{|c|}{$24 \mathrm{~h}$} & \multicolumn{3}{|c|}{$48 \mathrm{~h}$} & \multicolumn{3}{|c|}{$96 \mathrm{~h}$} \\
\hline $\mathrm{EC}_{50}(\mu \mathrm{L} / \mathrm{mL})$ & & $95 \%$ Conf Int & $\mathrm{EC}_{50}(\mu \mathrm{L} / \mathrm{mL})$ & & $95 \%$ Conf Int & $\mathrm{EC}_{50}(\mu \mathrm{L} / \mathrm{mL})$ & & 95\% Conf Int \\
\hline 30.686 & 1.426 & $27.735-33.636$ & 23.531 & 11.241 & $0.276-46.781$ & 27.626 & 9.134 & $8.731-46.521$ \\
\hline \multicolumn{9}{|c|}{ WE of T. citriodorus on $M$. javanica } \\
\hline \multicolumn{3}{|c|}{$24 \mathrm{~h}$} & \multicolumn{3}{|c|}{$48 \mathrm{~h}$} & \multicolumn{3}{|c|}{$96 \mathrm{~h}$} \\
\hline $\mathrm{EC}_{50}(\mu \mathrm{L} / \mathrm{mL})$ & & $95 \%$ Conf Int & $\mathrm{EC}_{50}(\mu \mathrm{L} / \mathrm{mL})$ & & $95 \%$ Conf Int & $\mathrm{EC}_{50}(\mu \mathrm{L} / \mathrm{mL})$ & & $95 \%$ Conf Int \\
\hline 38.057 & 3.736 & $30.329-45.781$ & 27.914 & 2.557 & $22.582-33.246$ & na & - & - \\
\hline \multicolumn{9}{|c|}{ WE of T. citriodorus on M. incognita } \\
\hline \multicolumn{3}{|c|}{$24 \mathrm{~h}$} & \multicolumn{3}{|c|}{$48 \mathrm{~h}$} & \multicolumn{3}{|c|}{$96 \mathrm{~h}$} \\
\hline $\mathrm{EC}_{50}(\mu \mathrm{L} / \mathrm{mL})$ & & 95\% Conf Int & $\mathrm{EC}_{50}(\mu \mathrm{L} / \mathrm{mL})$ & & $95 \%$ Conf Int & $\mathrm{EC}_{50}(\mu \mathrm{L} / \mathrm{mL})$ & & $95 \%$ Conf Int \\
\hline 35.974 & 1.066 & $33.769-38.180$ & na & - & - & na & - & - \\
\hline
\end{tabular}

$\mathrm{EC}_{50}$ values were not calculated (na) they were outside the test concentration range.

\subsection{In Planta Nematicidal Activity and Secondary Effects on Tomato Plants}

When different $O$. vulgare powder quantities were used in the pot bioassay to assess for efficacy, a clear dose-response relationship was established and efficacy was evident at $5 \mathrm{~g} / \mathrm{kg}$ of soil (Figure 1) both in terms of root galls and female counts. Considering stem and root weights, no statistical differences were evident until the test concentration of $50 \mathrm{~g} / \mathrm{kg}$ of soil, which was proved to be phytotoxic for the tomato plants. 




(A)

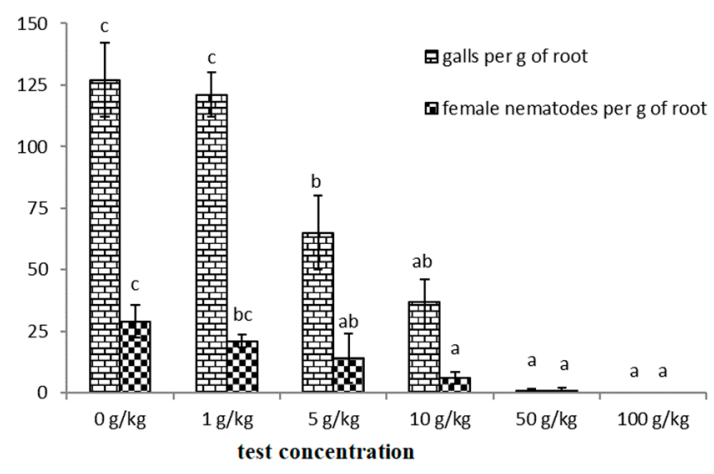

(B)

Figure 1. Tomato stem and root weights $(\mathrm{g})$, as assessed after treatment with $O$. vulgare powder for M. incognita control in pot bioassays 40 days after experiment establishment (A). Root galls and female counts per $\mathrm{g}$ of tomato root 40 days after experiment establishment (B). The data are means of ten replicates with standard deviations. Means followed by the same letter are not significantly different according to Duncan's test $(p \leq 0.05)$. Within each graph, letters correspond to statistical differences amongst same pattern bars.

\subsection{Chemical Composition Analysis of Water Extracts and Hydrosols of Lamiaceae Species-Nematicidal Activity Implication}

The GC-MS chemical analysis of the petroleum ether extracts of the WE and hydrosols unveiled several substances. More specifically, numerous constituents related to EOs of the respective species were identified. According to the GC-MS, the principal components in respective extracts were as follows: thymol in T. vulgaris WE $(89.15 \%)$, carvacrol in O. vulgare WE $(86.77 \%)$, eugenol and linalool in O. basilicum WE (50.75 and $34.45 \%$, respectively), carvacrol in O. vulgare $\mathrm{H}(93.00 \%)$, levomenthol in M. piperita $\mathrm{H}(54.35 \%)$, and thymol in M. officinalis $\mathrm{H}$ (39.43\%) (Table 2). Therefore, the predominant detections in the most active species (Thymus spp. and O. vulgare) were carvacrol and thymol. Carvacrol in O. vulgare WE and $\mathrm{H}$ displayed a profound difference in abundance from thymol.

Previously, we have demonstrated the significant individual nematicidal activity of carvacrol, along with its synergic potency with other terpenes, against Meloidogyne sp. [13,18]. Similarly, carvacrol has been proved to be a nematicidal component against $M$. incognita by others [29]. Interestingly, although $\mathrm{O}$. vulgare $\mathrm{H}$ was richer in terms of number of constituents compared to its WE, it exhibited higher $\mathrm{EC}_{50}$ values-a fact that reveals the complexity of bioactivity interactions amongst plant secondary metabolites within an extract.

In specific, based on the abundances of the key constituents of the GC-MS chromatograms (same plant material quantity used), the $\mathrm{H}$ contains higher concentrations of carvacrol and thymol than the WE; however, the WE is more potent than the H. Likewise, M. piperita $\mathrm{H}$ did not exhibit significant activity, although it yielded numerous ingredients considered active on Meloidogyne sp., like pulegone and geraniol $[13,18]$.

Lamiaceae species' EOs, extracts, hydrosols, and contained constituents are reported to exhibit nematicidal activity [13,30-34]. It is worth mentioning that, in this work, emphasis was given to the volatile and semivolatile constituents of the specific species, since many of these constituents display nematicidal activity. Nevertheless, it is expected that some of the semipolar and polar liquid-chromatography-amenable compounds (such as phenolic acids and flavonoids) can contribute to the nematicidal properties exhibited in this work. Therefore, the enhanced activity of O. vulgare WE and T. citriodorus WE might be attributed to the potential high content of phenolic acids (such as rosmarinic acid and oleanolic acid) that exhibit nematicidal properties $[32,35,36]$ and other phenolic compounds, including their glycosides and hexosides. 
Table 2. Chemical and relative composition of water extract (WE) and hydrosol (H) of Lamiaceae species *.

\begin{tabular}{|c|c|c|c|c|c|c|c|c|}
\hline \multirow[b]{2}{*}{$\begin{array}{l}\text { Retention } \\
\text { Time (min) }\end{array}$} & \multirow[b]{2}{*}{$\mathbf{R I}^{* *}$} & \multirow[b]{2}{*}{ Analyte } & \multicolumn{3}{|c|}{ WE $^{* * *}$ (Relative Amount (\%)) } & \multicolumn{3}{|c|}{$\mathrm{H}^{* *}$ (Relative Amount $(\%)$ ) } \\
\hline & & & Thymus vulgaris & Origanum vulgare & Ocimum basilicum & Origanum vulgare & Mentha piperita & Melissa officinalis \\
\hline 4.52 & $838(841)$ & Tyranton & & & & & $(0.80 \pm 0.13)$ & $(2.06 \pm 0.18)$ \\
\hline 9.48 & - & Trifluoro-acetyl- $\alpha$-terpineol & & & $(4.60 \pm 0.27)$ & & & \\
\hline 9.49 & $1032(1031)$ & Eucalyptol & & & & $(0.08 \pm 0.02)$ & $(10.19 \pm 0.93)$ & \\
\hline 10.81 & $1086(1091)$ & trans-Linalool-oxide (furanoid) & & & & $(0.03 \pm 0.01)$ & $(1.22 \pm 0.14)$ & \\
\hline 11.24 & 1090 (1090) & $\begin{array}{l}\text { Ethyl-2-(5-methyl-5-vinyltetrahydrofuran- } \\
\text { 2-yl)-propan-2-yl-carbonate }\end{array}$ & & & & & $(0.34 \pm 0.07)$ & \\
\hline 11.67 & 1099 (1100) & Linalool & & & $(34.45 \pm 2.27)$ & $(0.23 \pm 0.04)$ & $(5.64 \pm 0.35)$ & $(3.89 \pm 0.42)$ \\
\hline 12.27 & 1116 (1118) & trans-p-Mentha-2,8-dienol & & & & & & $(1.81 \pm 0.20)$ \\
\hline 12.28 & $1122(1123)$ & cis-2p-Menthen-1-ol & & & & & $(0.35 \pm 0.06)$ & \\
\hline 12.76 & $1123(1122)$ & 1R,4R-p-Mentha-2,8-dien-1-ol & & & & & & $(2.41 \pm 0.27)$ \\
\hline 13.01 & $1140(-)$ & (E)-p-2-Menthen-1-ol) & & & & & & $(1.07 \pm 0.10)$ \\
\hline 13.02 & 1146 (1146) & Isopulegol & & & & & $(0.84 \pm 0.09)$ & \\
\hline 13.23 & 1164 (1164) & cis-p-Menthan-3-one & & & & & $(1.57 \pm 0.23)$ & \\
\hline 13.54 & $1166(1166)$ & p-Menthan-3-one & & & & & $(3.24 \pm 0.30)$ & \\
\hline 13.68 & 1168 (1173) & (+)-Borneol & & & & & $(4.61 \pm 0.38)$ & \\
\hline 13.71 & $1167(-)$ & p-Mentha-1,5-dien-8-ol & & & & & & $(4.95 \pm 0.54)$ \\
\hline 13.77 & $1167(-)$ & endo-Borneol & & & & $(0.46 \pm 0.10)$ & & \\
\hline 14.01 & 1177 (1177) & Terpinen-4-ol & & & & $(0.73 \pm 0.11)$ & & $(5.25 \pm 0.31)$ \\
\hline 14.01 & 1175 (1172) & Levomenthol & & & & & $(54.35 \pm 4.17)$ & \\
\hline 14.02 & $1182(1182)$ & (-)-Terpinen-4-ol & & & $(10.20 \pm 0.80)$ & & & \\
\hline 14.31 & $1180(1180)$ & m-Cymen-8-ol & & & & $(0.27 \pm 0.03)$ & & \\
\hline 14.45 & 1190 (1187) & L- $\alpha$-Terpineol & & & & & $(5.70 \pm 0.44)$ & \\
\hline 14.46 & $1183(1182)$ & p-Cymen-8-ol & & & & $(0.42 \pm 0.10)$ & & \\
\hline 14.63 & 1189 (1189) & $\alpha$-Terpineol & & & & $(0.15 \pm 0.04)$ & & $(12.45 \pm 0.75)$ \\
\hline 14.72 & 1217 (1217) & trans-Carveol & & & & & & $(3.73 \pm 0.19)$ \\
\hline 15.08 & $1222(1222)$ & 2-Thiaadamantan-4-ol & & & & & $(1.88 \pm 0.19)$ & \\
\hline 15.25 & $1228(1228)$ & D-Verbenone & & & & & & $(3.07 \pm 0.22)$ \\
\hline 15.67 & $1240(-)$ & Isogeraniol & & & & & & $(2.97 \pm 0.33)$ \\
\hline 15.78 & $1240(1242)$ & $\beta$-Citral & & & & & & $(5.22 \pm 0.40)$ \\
\hline 15.80 & 1237 (1236) & Pulegone & & & & & $(2.02 \pm 0.28)$ & \\
\hline 16.14 & - & unidentified & & & & $(0.12 \pm 0.03)$ & & \\
\hline 16.22 & 1250 (1249) & Thymoquinone & & $(2.24 \pm 0.19)$ & & $(0.16 \pm 0.04)$ & & \\
\hline 16.24 & $1253(1252)$ & Piperitone & & & & & $(4.74 \pm 0.14)$ & \\
\hline 16.40 & 1255 (1258) & Geraniol & & & & & & $(6.68 \pm 0.57)$ \\
\hline 16.63 & - & p-Menthan-1,2,3-triol & & & & & $(1.35 \pm 0.22)$ & \\
\hline 16.69 & $1276(-)$ & Citral & & & & & & $(5.02 \pm 0.17)$ \\
\hline 17.57 & $1291(1292)$ & Thymol & $(89.15 \pm 5.10)$ & $(10.98 \pm 0.75)$ & & $(4.36 \pm 0.68)$ & & $(39.43 \pm 2.09)$ \\
\hline 18.04 & 1299 (1298) & Carvacrol & $(11.85 \pm 2.13)$ & $(86.77 \pm 3.15)$ & & $(93.00 \pm 3.17)$ & & \\
\hline 19.72 & 1357 (1358) & Eugenol & & & $(50.75 \pm 1.56)$ & & & \\
\hline
\end{tabular}

* Thymus citriodorus WE displayed traces of thymol, and Rosmarinus officinalis WE had no essential oil components; ** RI, retention index on HP5-MS UI column (relative to $n$-alkanes), identification based on mass spectra comparison with the reference databases and comparison with literature RIs obtained in equivalent column (depicted in parentheses); **** positive findings are indicated. 


\section{Conclusions}

The Mediterranean basin constitutes a chemical arsenal owing to its wealth of self-sown, aromatic plants which could be used for the development of "low-risk" plant protection products and "basic substances". As the EO manufacturing industry grows, producers are imposing plans, strategies, and technology for waste management and reutilization. The reutilization of this waste for the production of a new generation of nematicides constitutes an utterly successful practice not only for plant protection but also for the environment. Our results show that the easily prepared water extracts of $T$. citriodorus and O. vulgare, along with the distillation waste of $O$. vulgare, can be alternatives for the control of Meloidogyne. Additionally, plant powder of these two species incorporated into nematode-infested soil blocks infestation augmentation and can thus be an additional practice for farmers to incorporate into an integrated nematode management frame.

Author Contributions: Conceptualization, N.G.N.; methodology, N.G.N., E.X.O., K.M.K. and M.S.; software, N.G.N. and K.M.K.; validation, N.G.N., E.X.O., K.M.K. and S.K.G.; formal analysis, N.G.N. and K.M.K.; investigation, N.G.N., E.X.O., K.M.K. and M.S.; resources, M.S.; data curation, N.G.N. and K.M.K.; writing-original draft preparation, N.G.N. and S.K.G.; writing-review and editing, N.G.N., K.M.K. and S.K.G.; supervision, N.G.N. All authors have read and agreed to the published version of the manuscript.

Funding: This research received no external funding.

Acknowledgments: The authors are grateful to T. Koufakis and AGRIS SA for providing seeds and seedlings. We are also grateful to Aitheria Company, based in Velvento, Kozani, Greece, and Ethericon Greek Herbs Company, based in Larisa, Greece, for the kind offer of aromatic material.

Conflicts of Interest: The authors declare no conflict of interest.

\section{References}

1. Chitwood, B.G. The English word «Nema» revised. Syst. Zool. 1957, 6, 184-186. [CrossRef]

2. Hirschmann, H. Gross Morphology on Nematodes. In Nematology; Sasser, J.N., Jenkins, W.R., Eds.; California Univ. Press: Berkeley, CA, USA, 1960; pp. 125-129.

3. Trudgill, D.L.; Blok, V.C. Apomictic polyphagous root-knot nematodes; exceptionally successful and damaging biotrophic root pathogens. Annu. Rev. Phytopathol. 2001, 39, 53-77. [CrossRef] [PubMed]

4. Jones, J.T.; Haegeman, A.; Danchin, E.G.J.; Gaur, H.S.; Helder, J.; Jones, M.G.K.; Kikuchi, T.; Manzanilla-López, R.; Palomares-Rius, J.E.; Wesemael, W.M.L.; et al. Top 10 plant-parasitic nematodes in molecular plant pathology. Mol. Plant Pathol. 2013, 14, 946-961. [CrossRef] [PubMed]

5. Back, M.A.; Haydock, P.P.J.; Jenkinson, P. Disease complexes involving plant-parasitic nematodes and soilborne pathogens. Plant Pathol. 2002, 51, 683-697. [CrossRef]

6. Lambert, K.; Bekal, S. Introduction to plant-parasitic nematodes. Plant Health Instr. 2002, 10, $1094-1218$. [CrossRef]

7. European Commission. Regulation (EC) No 1107/2009 of the European 515 Parliament and of the Council of 21 October 2009 concerning the placing of plant 516 protection products on the market and repealing Council Directives 79/117/EEC 517 and 91/414/EEC. Off. J. Eur. Union 2009, 309, 1-50.

8. Isman, M.B. Plant essential oils for pest and disease management. Crop Prot. 2000, 19, 603-608. [CrossRef]

9. Karamanoli, K.; Menkissoglu-Spiroudi, U.; Bosabalidis, A.M.; Vokou, D.; Constantinidou, H.I.A. Bacterial colonization of the Phyllosphere of nineteen plant species and antimicrobial activity of their leaf secondary metabolites against leaf associate bacteria. Chemoecology 2005, 15, 59-67. [CrossRef]

10. Figueiredo, A.C.; Barroso, G.J.; Pedro, L.G.; Scheffer, J.J.C. Factors affecting secondary metabolite production in plants: Volatile components and essential oils. Flavour Fragr. J. 2008, 23, 213-226. [CrossRef]

11. Papachristos, D.P.; Karamanoli, K.I.; Stamopoulos, D.C.; Menkissoglu-Spiroudi, U. The relationship between the chemical composition of three essential oils and their insecticidal activity against Acanthoscelides obtectus (Say). Pest Manag. Sci. 2004, 60, 514-520. [CrossRef]

12. Al-Banna, L.; Darwish, R.M.; Aburjai, T. Effect of plant extracts and essential oils on root-knot nematodes. Phytopathol. Mediterr. 2003, 42, 123-128. 
13. Ntalli, N.G.; Ferrari, F.; Giannakou, I.; Menkissoglu-Spiroudi, U. Phytochemistry and nematicidal activity of the essential oils from 8 greek lamiaceae aromatic plants and 13 terpene components. J. Agric. Food Chem. 2010, 58, 7856-7863. [CrossRef] [PubMed]

14. Laquale, S.; Sasanelli, N.; D’Addabbo, T. Attività Biocida Di Olii Essenziali di Specie di Eucalyptus nei Confronti del Nematode Galligeno Meloidogyne Incognita. In Proceedings of the I Congresso Nazionale della Società Italiana per la Ricerca sugli Oli Essenziali (S.I.R.O.E.), Roma, Italy, 15-17 November 2013.

15. Laquale, S.; Candido, V.; Avato, P.; Argentieri, M.P.; D'Addabbo, T. Essential oils as soil biofumigants for the control of the root-knot nematode Meloidogyne incognita on tomato. Ann. Appl. Biol. 2015, 167, 217-224. [CrossRef]

16. Faria, J.M.S.; Sena, I.; Ribeiro, B.; Rodrigues, A.M.; Maleita, C.M.N.; Abrantes, I.; Bennett, R.; Mota, M.; Figueiredo, A.C.S. First report on Meloidogyne chitwoodi hatching inhibition activity of essential oils and essential oils fractions. J. Pest Sci. 2016, 89, 207-217. [CrossRef]

17. Lahlou, M. Methods to study the phytochemistry and bioactivity of essential oils. Phytother. Res. 2004, 18, 435-448. [CrossRef] [PubMed]

18. Ntalli, N.G.; Ferrari, F.; Giannakou, I.; Menkissoglu-Spiroudi, U. Synergistic and antagonistic interactions of terpenes against Meloidogyne Incognita and the nematicidal activity of essential oils from seven plants indigenous to Greece. Pest Manag. Sci. 2011, 67, 341-351. [CrossRef]

19. Mohan, S.Z.; Haider, H.C.; Andola, V.K. Essential oils as green pesticides: For sustainable agriculture. Res. J. Pharm. Biol. Chem. Sci. 2011, 2, 100-106.

20. Ehlers, R.-U. Regulation of Biological Control Agents; Springer: Cham, Switzerland, 2011; pp. 293-294.

21. Concerning the Data Requirements for Active Substances of Plant Protection Products Made from Plants or Plant Extracts; Sanco/10472/2003-rev.5; European Commission, Health \& Consumer Protection Directorate-General: Brussels, Belgium, 2014.

22. Working Document on the Procedure for Application of Basic Substances to Be Approved in Compliance with Article 23 of Regulation (EC) No 1107/2009; SANCO/10363/2012-rev.9; European Commission, Health \& Consumers Directorate-General: Brussels, Belgium, 2014.

23. Ntalli, N.; Bratidou Parlapani, A.B.; Tzani, K.; Samara, M.; Boutsis, G.; Dimou, M.; Menkissoglu-Spiroudi, U.; Monokrousos, N. Thymus Citriodorus (Schreb) Botanical Products as Ecofriendly Nematicides with Bio-Fertilizing Properties. Plants 2020, 9, 202. [CrossRef]

24. Hussey, R.S.; Barker, K.R. A comparison of methods of collecting Inocula of Meloidogyne spp. including a new technique. Plant Dis. Rep. 1973, 57, 1025-1028.

25. Byrd, D.W.; Krikpatrick, T.; Barker, K.R. An improved technique for cleaning and staining plant tissue for detection of nematodes. J. Nematol. 1983, 15, 142-143.

26. Puntener, W. Manual for Field Trials. In Plant Protection; Ciba-Geigy: Basel, Switzerland, 1981; p. 205.

27. Seefeldt, S.S.; Jensen, J.E.; Fuerst, E.P. Log-logistic analysis of herbicide rate response relationships. Weed Technol. 1995, 9, 218-227. [CrossRef]

28. Said, K.A.M.; Yakub, I.; Alipah, N.A.M. Effects of Solvent/Solid Ratio and Temperature on the Kinetics of Vitamin C Extraction from Musa Acuminata. J. Appl. Sci. Process Eng. 2015, 2, 107-115.

29. Nasiou, E.; Giannakou, I.O. The potential use of carvacrol for the control of Meloidogyne javanica. Eur. J. Plant Pathol. 2017, 149, 415-424. [CrossRef]

30. Andres, M.F.; Gonzalez-Coloma, A.; Munoz, R.; De la Pena, F.; Julio, L.F.; Burillo, J. Nematicidal potential of hydrolates from the semi industrial vapor-pressure extraction of Spanish aromatic plants. Environ. Sci. Pollut. Res. 2018, 25, 29834-29840. [CrossRef]

31. Barbosa, P.; Lima, A.S.; Vieira, P.; Dias, L.S.; Tinoco, M.T.; Barroso, J.G.; Pedro, L.G.; Figueiredo, A.G.; Mota, M. Nematicidal activity of essential oils and volatiles derived from Portuguese aromatic flora against the pinewood nematode, Bursaphelenchus xylophilus. J. Nematol. 2010, 42, 8-16.

32. Caboni, P.; Saba, M.; Tocco, G.; Casu, L.; Murgia, A.; Maxia, A.; Menkissoglu-Spiroudi, U.; Ntalli, N. Nematicidal Activity of Mint Aqueous Extracts against the Root-Knot Nematode Meloidogyne incognita. J. Agric. Food Chem. 2013, 61, 9784-9788. [CrossRef]

33. Andres, M.F.; Gonzalez-Coloma, A.; Sanz, J.; Burillo, J.; Sainz, P. Nematicidal activity of essential oils: A review. Phytochem. Rev. 2012, 11, 371-390. [CrossRef]

34. Pandey, A.K.; Singh, P.; Tripathi, N.N. Chemistry and bioactivities of essential oils of some Ocimum species: An overview. Asian Pac. J. Trop. Biomed. 2014, 4, 682-694. [CrossRef] 
35. Wang, J.; Pan, X.; Han, Y.; Guo, D.; Guo, Q.; Li, R. Rosmarinic Acid from Eelgrass Shows Nematicidal and Antibacterial Activities against Pine Wood Nematode and Its Carrying Bacteria. Mar. Drugs 2012, 10, 2729-2740. [CrossRef]

36. Qamar, F.; Begum, S.; Raza, S.M.; Wahab, A.; Siddiqui, B.S. Nematicidal natural products from the aerial parts of Lantana camara Linn. Nat. Prod. Res. 2005, 19, 609-613. [CrossRef] 